ISSN: 2304-0335 DOI: https://doi.org/10.17162/au.v12i2.1047

\title{
Propiedades psicométricas de la versión turca del cuestionario de agotamiento del atleta
}

\section{Psychometric properties of the Turkish version of the athlete burnout questionnaire}

\author{
Funda Koçak, ${ }^{\text {a }}$ Soner Sivri, ${ }^{2}$ Thomas D. Raedeke, ${ }^{3}$ Çalık Veli Koçak, ${ }^{4}$ \\ Oğuz Özbek ${ }^{5}$ \\ Ankara University, Faculty of Sport Sciences, Turkey ${ }^{1}$ \\ Burdur Mehmet Akif Ersoy University, Faculty of Sport Sciences, Turkey ${ }^{2}$ \\ East Carolina University, Department of Kinesiology, USA ${ }^{3}$ \\ Aksaray University, Faculty of Sport Sciences, Turkey ${ }^{4}$ \\ Ankara University, Faculty of Sport Sciences, Turkey ${ }^{5}$ \\ ID ORCID ID: https://orcid.org/0000-0001-5029-3006 ${ }^{1}$ \\ (iD ORCID ID: https://orcid.org/0000-0002-7966-21912 \\ DORCID ID: https://orcid.org/0000-0002-7511-4681 3 \\ ORCID ID: https://orcid.org/0000-0002-1403-0812 \\ iD ORCID ID: https://orcid.org/0000-0001-5185-9681 5
}

Recibido: 11 de setiembre de 2021

Aceptado: 18 de diciembre de 2021

\section{Resumen}

Este estudio tuvo como objetivo evaluar la evidencia de validez y confiabilidad de la versión turca del Athlete Burnout Questionnaire (ABQ). El ABQ incluye tres subescalas de 5 ítems que evalúan el agotamiento emocional/físico, la reducción del sentido de logro y la devaluación del deporte. Los participantes fueron 429 atletas con edades comprendidas entre los 13 y los 29 años $\left(\mathrm{M}_{\text {edad }}=17,68, D T=3,81\right)$. De la muestra, 178 eran mujeres $\left(\mathrm{M}_{\text {edad }}=16.92, D T=3.61\right) \mathrm{y}$ 251 eran hombres $\left(M_{e d a d}=23.23, D T=3.92\right)$. Una muestra separada de 208 atletas $(35,1 \%$ de baloncesto; $32,2 \%$ de voleibol; 20,4\% de natación; $12,3 \%$ de tenis) completó el cuestionario por segunda vez entre 13 y 16 días después de la aplicación inicial para evaluar la confiabilidad de la prueba-reprueba. Tanto los coeficientes Cronbach's Alpha como los valores de confiabilidad compuestos respaldaron la consistencia interna de la escala. En general, la evidencia de validez y confiabilidad fue similar a los hallazgos derivados del ABQ original. Estos hallazgos sugieren que las puntuaciones derivadas de la versión turca del $A B Q$ proporcionan una herramienta adecuada para evaluar el agotamiento del atleta.

Palabras claves: Burnout, deporte, medición, fiabilidad, validez, Turquia.

\begin{abstract}
This study aimed to evaluate validity and reliability evidence of the Turkish version of the Athlete Burnout Questionnaire (ABQ). The ABQ includes three 5-item subscales assessing emotional/physical exhaustion, reduced sense of accomplishment and sport devaluation. Participants were 429 athletes ranging from 13 to 29 years of age $(M$ age $=17.68, S D=3.81)$. Of the sample, 178 were female $(M$ age $=16.92, S D=3.61)$ and 251 were male $(M$ age $=23.23$, $S D=3.92)$. A separate sample of 208 athletes $(35.1 \%$ basketball; $32.2 \%$ volleyball; $20.4 \%$
\end{abstract}

${ }^{\mathrm{a} C o r r e s p o n d e n c i a ~ a l ~ a u t o r ~}$

E-mail: Funda.Kocak@ankara.edu.tr 
swimming; $12.3 \%$ tennis) completed the questionnaire a second time between 13 and 16 days after the initial application to evaluate test-retest reliability. Both Cronbach's Alpha coefficients and composite reliability values supported the scale's internal consistency. Overall, validity and reliability evidence was similar to findings stemming from the original ABQ. These findings suggest that scores derived from Turkish version of the ABQ provide a suitable tool for assessing athlete burnout.

Keywords: Burnout, sport, measurement, reliability, validity, Turkey.

\section{Introduction}

The burnout construct originated in the human services when it received attention based on Freudenberger's (1974) and Maslach's (1976) descriptions of a state of exhaustion resulting from chronic stress that is accompanied by disillusionment and a loss motivation. Subsequently, Maslach and Jackson (1981) operationally defined burnout as a "syndrome of depersonalization, emotional exhaustion and reduced personal accomplishment that can occur among individuals who do people work of some kind" (p.99). Emotional exhaustion was considered the most central feature of burnout in which individuals felt extreme fatigue, emotionally burdened, and depleted by one's work (Maslach et al. 1996). A reduced sense of personal accomplishment was defined as feelings of incompetence and being ineffective in one's ability to provide adequate care to others.

Soon thereafter, athlete burnout began to receive attention in the sport community (Coakley, 1992; Schmidt \& Stein, 1991). Sport psychologists recognized that the modern sport culture is replete with qualities that may make burnout likely. Not only does sport participation requires a great deal of motivation, it is also potentially stressful due to high training volumes, near year round training, and intense competitive demands. In addition, athletes may experience social pressure from important others such as coaches, parents, and fans. Scholars also recognized that burnout potentially has a negative impact on the quality of athletes' sport experiences, motivation, and performance which may result in athletes dropping out of sport (Raedeke et al. 2014). In addition, burnout was presumed to have a negative impact on athletes' physical health and psychological well-being (Gustafsson et al. 2017).

Although burnout was recognized as an important issue in the sport community, empirical inquiry was initially limited by a lack of operational definition and assessment tool. Raedeke (1997) noted the MBI was not directly applicable to athletes given the contextual differences between the role of an athlete and that of human service providers. Consequently, this author adapted the syndrome-based burnout conceptualization to fit the athlete role. 
Emotional exhaustion was extended to include physical fatigue stemming from training and competition. Reduced sense of accomplishment was described by feelings of inefficacy and a tendency to evaluate oneself negatively in terms of sport performance, skills, and ability rather than in terms of relationships. Given that depersonalization represents devaluation of and detachment from what is important in a given setting, such as the patients in human service settings, Raedeke noted this dimension reflects sport devaluation for athletes. This dimension was described as athletes developing a negative attitude, cynical outlook on sport, and psychological detachment to the point of developing a resentful attitude toward involvement sport.

For the other hand, the conceptual foundation of the ABQ also aligns with athlete and coach perspectives on this issue. In a qualitative study, Raedeke et al. (2002) found that conceptual foundation of the ABQ aligned with coaches' views on the nature of burnout. The ABQ is also consistent with athlete descriptions of burnout (e.g., Cresswell \& Eklund, 2006; Dubu, et al. 2010; Gustafsson et al. 2007).

Currently the $\mathrm{ABQ}$ is the most widely used tool in sport to measure athlete burnout (Eklund \& DeFreese, 2015; Gustafsson et al. 2014). According to the data of Web of Science (WOS) 2021, the study by Raedeke and Smith (2001) is the most cited study when searching with the keyword "athlete burnout" (WOS, 2021). Not only is the ABQ used frequently within English speaking countries, it has also been adapted to other languages and cultures including Arabic, Chinese, French, German, Japanese, Norwegian, Portuguese, Spanish, Swedish, and Taiwanese (Raedeke et al. 2014).

Given the potential impact burnout has on sport continuation and athlete well-being, athlete burnout has potential public health and epidemiological significance given the number of athletes that may potentially experience it (Gustafsson et al. 2011). According to 2018 data from the Ministry of Youth and Sports which organizes sport in Turkey, there are about 5 million athletes with approximately seven hundred thousand active athletes (Ministry of Youth and Sports, 2019). Consequently, burnout could potentially impact a large number of athletes. Burnout studies in Turkey may help identify athletes at risk of suffering from the syndrome as well as serve as the foundation for designing and implementing interventions to prevent its occurrence. Therefore, the present study was conducted to examined validity and reliability evidence of the ABQ's Turkish form in non-football sports and the study groups age similar with original $\mathrm{ABQ}$. In effort to increase scale generalizability, a large sample of athletes from various sports outside of football were included in the current study. 


\section{Methods}

\section{Participants}

Participants for this study were 429 athletes ranging from 13 to 29 years of age $(M=17.68$, $S D=3.81)$. Of the sample, 178 were female $(M$ age $=16.92, S D=3.61)$ and 251 were male $(M$ age $=23.23$, $S D=3.92$ ). In terms of sports represented, $17.7 \%$ competed in athletics, $16.8 \%$ in handball, $16.6 \%$ in swimming, $15.2 \%$ in volleyball, 9.3 in tennis, $6.3 \%$ in hockey, $5.4 \%$ in badminton, $4.4 \%$ in basketball, $4.2 \%$ in table tennis, $0.7 \%$ in combat sports and $3.5 \%$ in other sport types. They engaged in physical training an average of 4.59 days per week $(S D=1.45)$ for 2.17 hours per session $(\mathrm{SD}=.54)$. Athletes who reported training less than three days per week were excluded from the study $(n=14)$. Table 1 . Type your title here.

\section{Measures}

The Athlete Burnout Questionnaire (ABQ) is a sychometric evidence associated with the use of the Athlete Burnout Scale (ABQ) was initially reported by Raedeke and Smith (2001). The original ABQ consists of three 5-item subscales measured using 5 point Likert items ranging from 1 (almost never) to 5 (almost always). The subscales include emotional and physical exhaustion (e.g. I feel physically worn out from [sport]), reduced sense of accomplishment (e.g. I am not performing up to my ability in [sport]), and devaluation (e.g. I'm not into [sport] like I used to be). Items 1 and 14 reversed scored. Consistent with the original $A B Q$, the translated Turkish version has 15 items with items 1 and 14 reversed score with each item rated on a 5point Likert scale ranging from 1 (almost never) to 5 (almost always). In addition to the ABQ, athletes answered demographic questions including age, gender, type of sport, national sporting status, frequency of weekly training session, duration of weekly training session.

\section{Procedures}

In order to adapt the scale to Turkish, permission was initially obtained from Raedeke via email. Subsequently, a serial approach was used in the language adaptation of the scale (Herrera et al. 1993). The original form of the ABQ was translated to Turkish by two researchers and five translators with high level expertise in English. Through this effort, a Turkish version of the ABQ form was created. The final version of the Turkish version of the scale was translated into English by native Turkish three speakers using a back translation method. Subsequently, the back translation was sent to the original developer of the ABQ to evaluate whether the back translated items captured the meaning of the original items. For field testing, 15 athletes with 
expertise in both English and Turkish language completed both the Turkish and English version of the ABQ. Athletes completed each measure 14-16 days apart to eliminate recall biases and a possible learning effect. Athletes completed the English version first followed by the Turkish version.

Following, the primary data from the study were collected from March to May 2017. Athletes were contacted through sport clubs in the city of Ankara, from which 443 were contacted. Participants received information regarding the study purpose and volunteers who agreed to participate were given an informed consent form prior to completing the survey. The scale was administered to all participants by a member of the research team. The ABQ took approximately 8-10 minutes to complete. A separate sample of 208 athletes from the different specialties (35.1\% basketball; $32.2 . \%$ volleyball; $20.4 \%$ swimming; $12.3 \%$ tennis) completed the questionnaire a second time between 13 and 16 days after the initial application to evaluate test-retest reliability.

\section{Data analysis}

Following preliminary descriptive data analyses, confirmatory factor analysis (CFA) was conducted using LISREL 8.80 to evaluate the fit of the proposed model to the data. Aligned with conventional guidelines for interpreting CFA results, we examined both absolute and incremental indices to judge model fit. Specifically, fit indices included $\chi 2, \chi 2 / \mathrm{df}$, root mean square error of approximation (RMSEA), goodness of fit index (GFI), adjusted goodness of fit index (AGFI), normed fit index (NFI), non-normed fit index (NNFI), comparative fit index (CFI) and Standardized Root Mean Square Residual (SRMR).

Although we used $\chi 2$, where a no significant value means the observed data are consistent with the proposed model, it is not uncommon for $\chi^{2}$ to be significant with a large sample, which can lead to rejection of an adequately fitting model (Hu \& Benter, 1998). Therefore, instead of using only $\chi^{2}$ statistics it is preferable to use $\chi 2 / \mathrm{df}$ ratio. Although there is no consensus regarding an acceptable ratio for this statistic, recommendations range from as high as 5.0 (Wheaton et al. 1977) to as low as 2.0 (Tabachnick \& Fidell, 2007). Kline (2005) suggest that a $\chi 2 / \mathrm{df} \geq 3$ indicates that the fit of the model is acceptable.

RMSEA and SRMR values below .06 indicate a good fit, whereas values smaller than .08 are interpreted as acceptable (Hu \& Bentler, 1998, Schermelleh-Engel et al. 2003). In addition to the overall fit, measures based on model comparison were used to evaluate the fit. Specifically, CFI, NFI, GFI and the NNFI values higher than .95 suggest a good fit with .90 an 
acceptable fit for NFI and the GFI (Anderson \& Gerbing 1988). For the AGFI, acceptable fit was set to .85 and good fit at .90 (Hu \& Bentler, 1999; Schermelleh-Engel et al. 2003). Marsh, Hau \& Wen (2004) note that these criteria to fit interpretation should not be applied as golden rules but more as heuristic guides. Finally, in interpreting factor loadings, if the value is fewer than .10 it demonstrates a small impact; if about .30 it shows a medium impact; and if higher than .50 it denotes a large impact (Kline, 2010).

A high Average Variance Extracted (AVE) value means the indicators are exactly converging around the latent construct (Nusair \& Hua, 2010). The value of AVE ideally should exceed .50 for all constructs (Hair et al., 1998). However, Fornell and Locker (1981) stated that when AVE is less than .50 but composite reliability $(\mathrm{CR})$ is greater than .60 , model fit is still acceptable if the AVE value is greater than .40.

Along with evaluating the internal consistency of the scale through Cronbach alpha and composite reliability coefficients, a subset of 208 athletes representing a variety of sports were sampled to evaluate test-retest reliability. A correlation of .80 indicates high agreement and .70 indicates acceptable agreement (Kline, 2005).

\section{Results}

Table 1 shows the original and translate ABQ items along with the subscale each item conceptually fits. 
Table 1

English, Turkish Version, and Back translated items of the $A B Q$

\begin{tabular}{|c|c|c|c|}
\hline Item & Factor & Original Item & Turkish Translation \\
\hline 1 & RSA & $\begin{array}{l}\text { I'm accomplishing many } \\
\text { worthwhile things in sport. }\end{array}$ & $\begin{array}{l}\text { [Sporda] kayda değer pek çok şey } \\
\text { başarıyorum. }\end{array}$ \\
\hline 2 & PEE & $\begin{array}{l}\text { I feel so tired from my } \\
\text { training that I have trouble } \\
\text { finding energy to do other } \\
\text { things. }\end{array}$ & $\begin{array}{l}\text { Antrenmanlarda çok yorulduğum için } \\
\text { başka şeyleri yapacak enerji bulmakta } \\
\text { zorlanıyorum. }\end{array}$ \\
\hline 3 & SD & $\begin{array}{l}\text { The effort I spend in sport } \\
\text { would be better spent doing } \\
\text { other things }\end{array}$ & $\begin{array}{l}\text { Başka şeyler için harcadığıı çaba [spora] } \\
\text { harcadığımdan daha iyidir. }\end{array}$ \\
\hline 4 & PEE & $\begin{array}{l}\text { I feel overly tired from my } \\
\text { sport participation. }\end{array}$ & $\begin{array}{l}\text { [Spordan] dolayı kendimi aşırı yorgun } \\
\text { hissediyorum. }\end{array}$ \\
\hline 5 & RSA & $\begin{array}{l}\text { I am not achieving much in } \\
\text { sport. }\end{array}$ & [Sporda] çok başarı elde edemiyorum. \\
\hline 6 & SD & $\begin{array}{l}\text { I don't care as much about } \\
\text { my sport performance as I } \\
\text { used to. }\end{array}$ & $\begin{array}{l}\text { [Spordaki] performansımı eskisi kadar } \\
\text { önemsemiyorum. }\end{array}$ \\
\hline 7 & RSA & $\begin{array}{l}\text { I am not performing up to } \\
\text { my ability in sport }\end{array}$ & $\begin{array}{l}\text { [Sporda], yeteneğim kadar performans } \\
\text { göstermiyorum. }\end{array}$ \\
\hline 8 & PEE & $\begin{array}{l}\text { I feel 'wiped out' from } \\
\text { sport }\end{array}$ & [Spordan] dolayı bitkin hissediyorum. \\
\hline 9 & SD & $\begin{array}{l}\text { I'm not into sport like I } \\
\text { used to be }\end{array}$ & [Spordan] eskisi kadar hoşlanmıyorum. \\
\hline 10 & PEE & $\begin{array}{l}\text { I feel physically worn out } \\
\text { from sport. }\end{array}$ & $\begin{array}{l}\text { [Spordan] dolayı kendimi fiziksel olarak } \\
\text { yıpranmıs hissediyorum. }\end{array}$ \\
\hline 11 & SD & $\begin{array}{l}\text { I feel less concerned about } \\
\text { being successful in sport } \\
\text { than I used to. }\end{array}$ & $\begin{array}{l}\text { [Sporda] başarll olma konusunda eskisi } \\
\text { kadar kayglanmıyorum. }\end{array}$ \\
\hline 12 & PEE & $\begin{array}{l}\text { I am exhausted by the } \\
\text { mental and physical } \\
\text { demands of sport. }\end{array}$ & $\begin{array}{l}\text { [Sporun] fiziksel ve zihinsel } \\
\text { gereksinimlerinden dolayı tükenmiş } \\
\text { durumdayım. }\end{array}$ \\
\hline 13 & RSA & $\begin{array}{l}\text { It seems that no matter what } \\
\text { I do, I don't perform as well } \\
\text { as I should. }\end{array}$ & $\begin{array}{l}\text { Ne yaparsam yapayım gerektiği kadar } \\
\text { performans gösteremiyorum. }\end{array}$ \\
\hline 14 & RSA & I feel successful at sport. & [Sporda] başarılı olduğumu hissediyorum. \\
\hline 15 & SD & $\begin{array}{l}\text { I have negative feelings } \\
\text { toward sport. }\end{array}$ & a] karşı olumsuz hi \\
\hline
\end{tabular}

RSA $=$ reduced sense of accomplishment

$\mathrm{PEE}=$ physical/emotional exhaustion

$\mathrm{SD}=$ sport devaluation

Items 1 and 14 are reverse-scored.

Results from the sample of 15 athletes completing both the English and Turkish scale versions revealed significant and strong correlations between factors on the two scale versions. 
The correlations between Turkish and English version of the scale was calculated for reduced sense of accomplishment factor .74, physical/emotional exhaustion factor .70, and sport devaluation factor .75 . This finding reveals that the consistency between two versions of the scale is acceptable and linguistic equivalence is achieved.

Table 2 displays descriptive statistics of mean, standard deviation, skewness and kurtosis values of scale 15 items $(\mathrm{N}=429)$. Across all three dimensions, burnout scores were in the low to moderate range. The reduced sense of accomplishment factor has slightly higher item means with values between 2.01 (item 13) and 2.28 (item 7) compared to the other two dimensions. In constrast, the sport devaluation factor has the lowest item means ranging from 1.73 (item 15) to 2.30 (item 11). The standard deviations range between 1.04 (item 13) and 1.32 (item 3). In general, positive skewness and a slight predominance of leptokurtic distributions were seen in the distribution of the items.

Table 2

Descriptive Statistics

\begin{tabular}{lccccc}
\hline Factor & Item & $M$ & $S D$ & Skewness & Kurtosis \\
& & & & & \\
\hline RSA & 1 & 2.22 & 1.06 & .75 & -.01 \\
& 5 & 2.20 & 1.05 & .70 & -.00 \\
& 7 & 2.28 & 1.19 & .57 & -.67 \\
& 13 & 2.01 & 1.04 & .91 & .20 \\
& 14 & 2.17 & 1.09 & .90 & .32 \\
& Total & $\mathbf{2 . 1 8}$ & $\mathbf{. 7 5}$ &. $\mathbf{3 9}$ & $\mathbf{- . 5 2}$ \\
& & & & & \\
PEE & 2 & 2.49 & 1.12 & .30 & -.64 \\
& 4 & 2.28 & 1.07 & .63 & -.04 \\
& 8 & 2.11 & 1.11 & .72 & -.31 \\
& 10 & 1.94 & 1.16 & 1.08 & .24 \\
& 12 & 1.78 & 1.10 & 1.27 & .59 \\
& Total & $\mathbf{2 . 1 2}$ & $\mathbf{. 8 7}$ & .77 &. $\mathbf{0 5}$ \\
SD & 3 & & & & \\
& 6 & 1.90 & 1.16 & .88 & -.48 \\
& 9 & 1.74 & 1.11 & 1.38 & .11 \\
& 11 & 2.30 & 1.32 & .60 & -.89 \\
& 15 & 1.73 & 1.16 & 1.52 & 1.22 \\
& Total & $\mathbf{1 . 9 6}$ & $\mathbf{. 8 2}$ & $\mathbf{. 7 8}$ & $\mathbf{- . 0 9}$ \\
\hline
\end{tabular}

RSA $=$ reduced sense of accomplishment

$\mathrm{PEE}=$ physical/emotional exhaustion $\mathrm{SD}=$ sport devaluation 


\section{Confirmatory factor analysis}

For this study, only the measurement model of the original scale was tested in order to remain aligned with the original measure. The factor loadings were significant, with values between .47 (item 1) and .93 (item 9 and item 10) (Table 3). Using a loading of .50 to indicate a high value, nearly all of the individual item factor loadings were large in magnitude. The three factors demonstrated moderately high interfactor correlations (Figure 1). Specifically, reduced sense accomplishment correlated .64 with physical/emotional exhaustion factor and .72 with sport devaluation. The highest correlation was between physical/emotional exhaustion factor and sport devaluation $\left(r_{\mathrm{xy}}=.85\right)$.

Table 3

Confirmatory Factor Analysis Estimations

\begin{tabular}{lcccccc}
\hline Factor & Item & $\begin{array}{c}\text { Factor } \\
\text { loading }\end{array}$ & t values & $R^{2}$ & CR & AVE \\
\hline RSA & 1 & .47 & 8.54 & .19 & & \\
& 5 & .72 & 14.13 & .31 & & \\
& 7 & .71 & 12.07 & .21 & .80 & .45 \\
& 13 & .76 & 15.38 & .37 & & \\
& 14 & .67 & 10.79 & .46 & & \\
PEE & 2 & .63 & 11.71 & .47 & & \\
& 4 & .65 & 12.84 & .35 & & \\
& 8 & .79 & 15.84 & .50 & .88 & .60 \\
& 10 & .93 & 18.68 & .68 & & \\
& 12 & .86 & 17.93 & .64 & & \\
SD & 3 & .60 & 9.24 & .18 & & \\
& 6 & .80 & 15.19 & .60 & & \\
& 9 & .93 & 19.34 & .52 & .85 & .53 \\
& 11 & .57 & 8.58 & .29 & & \\
& 15 & .70 & 12.77 & .36 & & \\
\hline
\end{tabular}

RSA $=$ reduced sense of accomplishment

$\mathrm{PEE}=$ physical/emotional exhaustion

$\mathrm{SD}=$ sport devaluation

The initial model fit indices were $\chi 2$ (340.92), $\chi 2 / \mathrm{df}$ (3.92), GFI (.90), AGFI (.86), RMSEA (.83), NFI (.937), NNFI (.943), CFI (.953), SRMR (.057). These findings indicate that the original model should be retested. Therefore, modification indices were used to develop the model. In evaluating modification indices, the largest modification values were used and their conceptual fit was taken into consideration. Modification indices suggested that measurement error may covary between items two and four and between four and eight on the 
physical/emotional exhaustion factor. Allowing the error in these questions to covary provided the best fitting model, both in terms of $\chi^{2}$ and all fit indices.

According to the final model, the t-values of all items were significant. Each dimension's composite reliability (CR) coefficient was acceptable with values ranging between .80 and .88 . Table 3 shows that AVE values ranged from 0.45 to 0.60 . Thus, AVE values confirm the convergent validity of the model. Examination of fit indices suggest that the threefactor structure of the scale provide an acceptable fit to the data (Figure 1). In this study, $\chi 2 / \mathrm{df}$ values were also significant $(\chi 2=276.81 \mathrm{df}=95$ but the $\chi 2 / \mathrm{df}$ ratio was below 3.0 (i.e., 2.91. $\mathrm{p}$ $<0.001)$ suggesting adequate fit (Kline 2005). The NFI (0.95), NNFI (0.96), CFI (0.96) also indicated a good model fit. The other three indices GFI (.92), RMSEA (.063) and SRMR (.054) were also in an acceptable range (Anderson \& Gerbing 1988; Hu \& Bentler 1998, SchermellehEngel et al. 2003). Although AGFI (.89) is found to be low in the study, it is within acceptable limits (Hu \& Bentler 1999, Schermelleh-Engel et al. 2003). Collectively, these results show the model provides an acceptable fit to the data. 


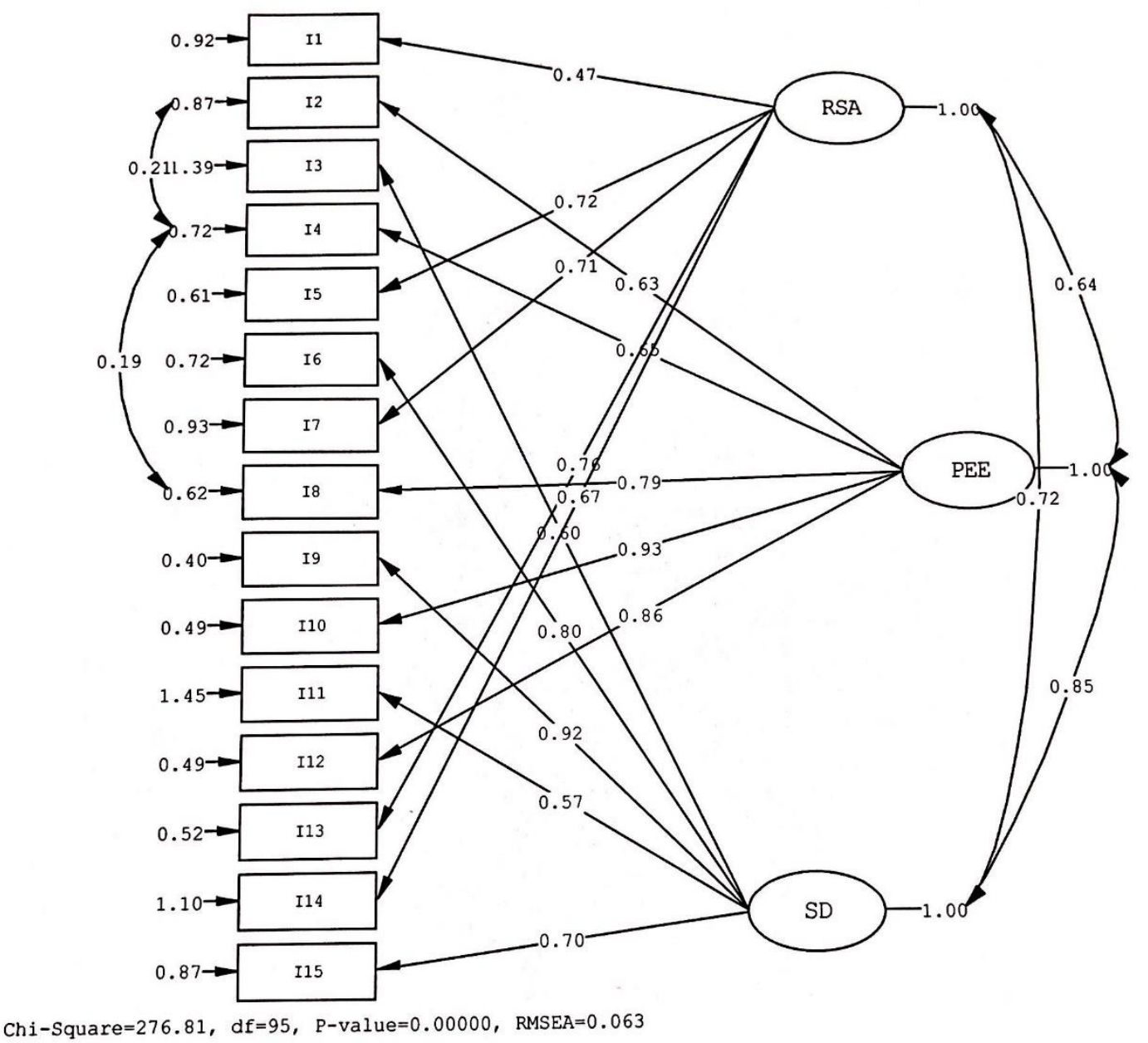

Figure 1. The factor structure and inter factor correlations of the three factors, 15 items model

\section{Reliability}

While recognizing the criticism associated with the use of Cronbach's alpha coefficients, they are commonly used to estimate internal consistency reliability and therefore are included in addition to composite reliability coefficients. Inspection of alpha coefficients indicate that all three subscales demonstrated adequate internal consistency using .70 as a guide to interpretation. The alpha coefficients were .84 for physical/emotional exhaustion, .72 for reduced sense of accomplishment, and .70 for sport devaluation. Inspecting item-factor correlations revealed moderate to moderate-high correlations between items and their corresponding factor. Analyses also revealed that removing items would not increase subscale reliability. The translated $\mathrm{ABQ}$ also demonstrated adequate test-retest reliability, .82 for physical/emotional exhaustion, .77 for sport devaluation and .74 for reduced sense of accomplishment (Table 4). 


\section{Table 4}

Analysis of items and reliability of the $A B Q$

\begin{tabular}{lcccc}
\hline \multicolumn{1}{c}{ Factor } & Item & $\begin{array}{c}\text { Corrected } \\
\text { item-factor } \\
\text { correlations }\end{array}$ & $\begin{array}{c}\text { Alpha if item } \\
\text { deleted }\end{array}$ & Test-retest reliability \\
\hline RSA & 1 & .36 & .71 & .71 \\
$\alpha=.72$ & 5 & .50 & .72 & .66 \\
$\mathrm{r}_{\mathrm{x} x}=.74$ & 7 & .47 & .80 & .64 \\
& 13 & .58 & .75 & .69 \\
& 14 & .43 & .76 & .66 \\
$\mathrm{PEE}$ & 2 & .50 & .86 & .62 \\
$\alpha=.84$ & 4 & .57 & .83 & .69 \\
$\mathrm{r}_{\mathrm{x} x}=.82$ & 8 & .61 & .81 & .69 \\
& 10 & .66 & .82 & .67 \\
& 12 & .66 & .85 & .51 \\
$\mathrm{SD}$ & & & & .60 \\
$\alpha=.70$ & 3 & .35 & .76 & .57 \\
$\mathrm{r} \times \mathrm{x}=.77$ & 9 & .59 & .73 & .64 \\
& 11 & .69 & .70 & .70 \\
& 15 & .58 & .71 & .75 \\
\hline
\end{tabular}

Note: The sample size for assessing internal consistency was $\mathrm{N}=429$ while the sample size for test-retest reliability was $n=208$

\section{Discussion}

The athlete burnout syndrome has gained international recognition. However, few studies have examined this syndrome within a Turkish culture, which may in part be due to the lack of a widely accepted assessment tool. Consequently, this study was designed to test the validity and reliability of the Turkish version of the Athlete Burnout Questionnaire (ABQ) developed by Raedeke and Smith (2001). CFA results confirmed the original structure of the scale with three factors providing an acceptable fit to the data. Results are similar to those of Raedeke and Smith (2001) in the United States sampling athletes from a variety of sport types. The specified factor structure also coincides with the adaptations of the scale in different cultures (Arce et al. 2012; Cresswell \& Eklund, 2006; Isoard-Gautheur et al. 2010; Lemyre et al. 2008). Although the first item (I'm accomplishing many worthwhile things in sport.) of the reduced sense of accomplishment factor loading is lower than the other items, it was viewed as acceptable and it was not removed from the Turkish ABQ in order to preserve the structure of the original $A B Q$.

In addition to providing construct validity evidence through examination of the scale's factor structure, reliability was also examined. Acceptable values were observed for both the 
internal consistency of the factors and the temporal stability of the responses to the questionnaire (test-retest). Using a cutoff of .70 to denote acceptable reliability (Field, 2013) the scale had acceptable internal consistency with alpha coefficients ranging from .70 to .84 across burnout dimensions. These values are similar or higher than those found in some research (Arce et al. 2012; Cresswell \& Eklund 2006; Fernández et al., 2012) but lower than those reported in other studies (Isoard-Gautheur et al., 2010; Raedeke \& Smith, 2001). Test--retest reliability values ranged from .74 (i.e., reduced sense of accomplishment, .77 (sport devaluation) to .82 (physical/emotional exhaustion).

Given the Turkish version of the ABQ has validity evidence surrounding its use in sport settings, future researchers may consider additional psychometric research designed to evaluate whether scale responses are invariant across cultures. Conducting such research would facilitate comparing research findings cross-culturally. The meaning of scores derived from the ABQ potentially may vary depending on cultural context. Even if the meaning of scores are invariant across cultures, it is possible that the mean level of burnout differs across cultures. Such findings may indicate potential differences in the prevalence of burnout that may be impacted by cultural factors (Maslach et al., 1996).

In addition to measurement research, future researchers may investigate potential antecedents and consequences of burnout within the cultural context of Turkey as few studies have done so and burnout is considered an important issue facing Turkish athletes (Demirci \& Çepikkurt, 2018; Koçak, 2019). Research examining the potential consequences of burnout in Turkish athletes may help establish the public health and epidemiologic significance of research on this issue. Examining potential antecedents of burnout may provide the foundation for developing interventions to prevent its occurrence. Although not specific to Turkish athletes, burnout is considered a stress related reaction that also involves motivational processes. Considerable research has shown that burnout is a reaction to chronic stress across a wide variety of settings including sport (Maslach et al. 2001). Chronic stress occurs when athletes perceive that the demands of sport participation exceed their ability to effectively manage those demands (Coakley, 1992). Demands stem from a variety of sources including training and competitive demands, pressure from significant others, internal pressures such as from perfectionism. In addition, coping resources including social support, lifestyle management, and mental skills may result in lower stress or buffer the effects of stress on burnout.

In addition, burnout has been linked to an erosion of motivation which is accompanied by a shift from more internal to external sources of motivation ( $\mathrm{Li}$ et al., 2013). With 
autonomous motivation athletes participate because they want to maintain involvement and they value the benefits of the activity and may be intrinsically motivated. In contrast with external sources of motivation, athletes participate due to internal or external pressures and feel they have to continue involvement. In addition, burnout has been examined from an achievement goal perspective. Conceptually, burnout risk is lower when athletes are mastery oriented or participate in a mastery oriented team culture and focus on self-reference standards of excellence such as improving their skills. In contrast, athletes who are more outcome oriented or participant a performance-oriented team culture where the focus is on winning and doing better than others may be at heightened risk for burnout (Cervelló et al. 2007). Research has also shown that significant others including coaches, teammates, and parents are linked to burnout in part due to their association with both stress and motivational processes (DeFreese \& Smith, 2013; Isoard-Gautheur et al., 2016).

Collectively, research outside of Turkish culture has identified a variety of factors associated with burnout including such as motivation, stress, enjoyment, happiness, social support, coping strategies, negotiation strategies, commitment, satisfaction, perceived control, perfectionism, and depression (Olsson et al., 2021; Scotto di Luzio et al., 2020). However, the extent to which those factors are related and centrally involved in burnout in Turkish athletes is unknown given that cultural factors potential impact burnout processes. Given that, in addition to examining burnout processes specifically within Turkish athletes, research might also employ cross-cultural research designs focused on understanding potential antecedents and consequences associated with burnout. Even if the burnout construct itself is similar across cultures, the specific antecedents and consequences associated with it may vary depending on cultural context. This is especially true given that cultural factors potentially influence motivational and stress processes, including the specific individual and environmental factors underlying burnout.

Ultimately, understanding athlete burnout within the Turkish culture and from a crosscultural perspective may facilitate developing intervention strategies designed to prevent burnout that are optimally tailored given cultural influences on burnout processes. Results from this study examining construct validity evidence of an assessment tool are the first step in that effort. The validity and reliability evidence stemming from the Turkish version of the ABQ are promising suggesting that this scale may be used to examine the prevalence of burnout, potential antecedents that can be targeted in interventions designed to prevent its occurrence, 
and consequences that may help establish the epidemiological/public health significance of studying burnout within Turkish athletes.

\section{Conclusion}

A Turkish version of the ABQ has been established with a 15 item-3 subscale format like original form developed by Raedeke and Smith (2001) including reduced sense of accomplishment, physical/emotional exhaustion and sport devaluation subscales. The Turkish version of $\mathrm{ABQ}$ (15 items) has similar characteristics to the original scale and its adaptations in other cultures. The fit indices and reliability of the questionnaire are adequate supporting its use scientific studies designed to advance the body of knowledge on this issue. It is an additional advantage that the present version can be used to assess athlete across a variety of sport types, ages, and gender in the Turkish culture because the sample used in the study consisted of female and male athletes representing 18 different individual and team sports who ranged in age between of 13 and 29. There were no conflicts of interest.

\section{References}

Anderson, J. C., \& Gerbing, D. W. (1988). Structural equation modeling in practice: A review and recommended two-step approach. Psychological bulletin, 103 (3), 411-423. doi:10.1037/0033-2909.103.3.411

Arce, C., de Francisco C., Andrade, E., Seoane, S., Raedeke, T. (2012). Adaptation of the athlete burnout questionnaire in a Spanish sample of athletes. The Spanish Journal of Psychology, 15 (3), 1529-1536. doi:10.5209/rev_SJOP.2012.v15.n3.39437

Cervelló, E. M.. Escartí. A.. \& Guzmán. J. F. (2007). Youth sport dropout from the achievement goal theory. Psicothema, 19 (1). 65-71.

Cresswell, S. L., \& Eklund, R. C. (2006). The nature of player burnout in rugby: Key characteristics and attributions. Journal of Applied Sport Psychology, 18 (3), 219-239. doi:10.1080/10413200600830299

Coakley, J. (1992). Burnout among adolescent athletes: A personal failure or social problem? Sociology of Sport Journal, 9 (3), 271-285. doi:10.1123/ssj.9.3.271

DeFreese, J. D., \& Smith, A. L. (2013). Teammate social support, burnout, and self-determined motivation in collegiate athletes. Psychology of sport and exercise, 14 (2), 258-265. doi:10.1016/j.psychsport.2012.10.009

Demirci, E., \& Çepikkurt, F. (2018). Examination of the Relationship between Passion, Perfectionism and Burnout in Athletes. Universal Journal of Educational Research, 6 (6), 1252-1259. doi:10.13189/ujer.2018.060616 
Dubuc, N. G., Schinke, R. J., Eys, M. A., Battochio, R., \& Zaichkowsky, L. (2010). Experiences of burnout among adolescent female gymnasts: three case studies. Journal of Clinical Sport Psychology, 4 (1), 1-18. doi:10.1123/jcsp.4.1.1

Eklund, R. C. \& DeFreese. J. D. (2015). Athlete Burnout: What we know what we could know and how we can find out more. International Journal of Applied Sports Sciences. 27 (2). 63-75. doi:10.24985/ijass.2015.27.2.63

Fernández, C. A., Palacios, C. D. F., Fernández, E. M. A., Otero, M. J. F., Raedeke, T. D., \& de Murcia, A. (2012). Adaptación del ABQ para la evaluación del burnout en deportistas colombianos. Revista Iberoamericana de psicología del ejercicio y el deporte, 7 (2), 271-286.

Field, A. (2013). Discovering statistics using IBM SPSS statistics: And sex and drugs and rock ' $n$ ' roll. (4th ed.), Los Angeles: Sage.

Fornell, C., \& Larcker, D. (1981). Evaluating structural equation models with unobservable variables and measurement error. Journal of Marketing Research, 18 (1), 39-50. doi: $10.2307 / 3151312$

Freudenberger, H. J. (1974). Staff burn-out. Journal of Social Issues, 30 (1), 159-165. doi:10.1111/j.1540-4560.1974.tb00706.x

Gustafsson, H., DeFreese, J. D., \& Madigan, D. J. (2017). Athlete burnout: Review and recommendations. Current opinion in psychology, 16, 109-113. doi:10.1016/j.copsyc.2017.05.002

Gustafsson, H., Hancock, D. J., \& Côté, J. (2014). Describing citation structures in sport burnout literature: A citation network analysis. Psychology of Sport and Exercise, 15 (6), 620-626. doi:10.1016/j.psychsport.2014.07.001

Gustafsson, H., Kenttä, G., Hassmén, P., \& Lundqvist, C. (2007). Prevalence of burnout in competitive adolescent athletes. The Sport Psychologist, 21 (1), 21-37. doi: 10.1123/tsp.21.1.21

Gustafsson, H., Kenttä, G., \& Hassmén, P. (2011). Athlete burnout: An integrated model and future research directions. International Review of Sport and Exercise Psychology, 4 (1), 3-24. doi:10.1080/1750984X.2010.541927

Hair, J., Anderson, R., Tatham, R., \& Black, W. (1998). Multivariate data analysis (5th ed.). Upper Saddle River, NJ: Prentice-Hall.

Herrera, R. S.. DelCampo. R. L.. \& Ames. M. H. (1993). A serial approach for translating family science instrumentation. Family relations. 42 (3), 357-360. doi:10.2307/585567

Hu, L. T., \& Bentler, P. M. (1998). Fit indices in covariance structure modelling: Sensitivity to under parameterized model misspecification. Psychological methods, 3 (4), 424-253. doi:10.1037/1082-989X.3.4.424

Hu, L. T., \& Bentler, P. M. (1999). Cut-off criteria for fit indexes in covariance structure analysis: Conventional criteria versus new alternatives. Structural equation modeling: a multidisciplinary journal, 6 (1), 1-55. doi:10.1080/10705519909540118 
Isoard-Gautheur, S., Oger, M., Guillet, E., \& Martin-Krumm, C. (2010). Validation of a French version of the Athlete Burnout Questionnaire (ABQ): In competitive sport and physical education context. European Journal of Psychological Assessment, 26 (3), 203-211. doi:10.1027/1015-5759/a000027

Isoard-Gautheur. S.. Trouilloud. D., Gustafsson. H. \& Guillet-Descas. E. (2016). Associations between the perceived quality of the coach-athlete relationship and athlete burnout: An examination of the mediating role of achievement goals. Psychology of sport and exercise, 22, 210-217. doi:10.1016/j.psychsport.2015.08.003

Kline, P. (2005). The handbook of psychological testing (2nd ed.) London, United Kingdom: Taylor and Francis.

Kline, R. B. (2010). Promise and pitfalls of structural equation modeling in gifted research. In B. Thompson \& R. F. Subotnik (Eds.), Methodologies for conducting research on giftedness (pp. 147-169). Washington DC, US: American Psychological Association.

Koçak, Ç. V. (2019). The relationship between self-efficacy and athlete burnout in elite volleyball players. Pedagogy of Physical Culture and Sports, 23 (5), 231-238. doi:10.15561/18189172.2019.0504

Lemyre, P. N., Hall, H. K., \& Roberts, G. C. (2008). A social cognitive approach to burnout in elite athletes. Scandinavian journal of medicine \& science in sports, 18 (2), 221-234. doi:10.1111/j.1600-0838.2007.00671.x

Li, C., Wang, C. J., Pyun D. Y., \& Kee, Y. H. (2013). Burnout and its relations with basic psychological needs and motivation among athletes: A systematic review and metaanalysis. Psychology of Sport and Exercise, $14 \quad$ (5), 692-700. doi:10.1016/j.psychsport.2013.04.009

Maslach, C. (1976). Burned-Out. Human behavior, 5 (9), 16-22.

Maslach. C.. \& Jackson. S. E. (1981). The measurement of experienced burnout. Journal of organizational behavior. 2 (2), 99-113. doi:10.1002/job.4030020205

Maslach, C., Jackson, S. E., \& Leiter, M. P. (1996). Maslach burnout inventory manual (Vol. 4). Palo Alto, CA: Consulting Psychologists Press.

Maslach. C.. Schaufeli. W. B. \& Leiter. M. P. (2001). Job burnout. Annual review of psychology. 52 (1), 397-422. doi:10.1146/annurev.psych.52.1.397

Marsh, H. W., Hau, K. T., \& Wen, Z. (2004). In search of golden rules: Comment on hypothesis-testing approaches to setting cut-off values for fit indexes and dangers in overgeneralizing $\mathrm{Hu}$ and Bentler's (1999) findings. Structural equation modeling, 11 (3), 320-341. doi:10.1207/s15328007sem1103_2

Ministry of Youth and Sports. (2019, July 22). Athletes in Turkey. http://sgm.gsb.gov.tr/Sayfalar/175/105/Istatistikler

Nusair, K., \& Hua, N. (2010). Comparative assessment of structural equation modeling and multiple regression research methodologies: E-commerce context. Tourism management, 31 (3), 314-324. doi:10.1016/j.tourman.2009.03.010 
Olsson, L. F., Madigan, D. J., Hill, A. P., \& Grugan, M. C. (2021). Do athlete and coach performance perfectionism predict athlete burnout? European Journal of Sport Science, 1-12. doi: 10.1080/17461391.2021.1916080

Raedeke, T. D. (1997). Is athlete burnout more than just stress? A sport commitment perspective. Journal of sport and exercise psychology. 19 (4), 396-417. doi:10.1123/jsep.19.4.396

Raedeke, T. D., \& Smith, A. L. (2001). Development and preliminary validation of an athlete burnout measure. Journal of sport and exercise psychology, 23 (4), 281-306. doi:10.1123/jsep.23.4.281

Raedeke, T.D., Smith, A, Kenttä, G., Arce, C., \& de Francisco, C. (2014). Burnout and commitment in sport: From theory to intervention. In A.R. Gomes, R. Resende, \& A. Albuquerque (Eds.), Positive Human Functioning from a Multidimensional Perspective: Promoting Stress Adaptation. New York, NJ: NOVA, pp. 113-142.

Schermelleh-Engel, K., Moosbrugger, H., \& Müller, H. (2003). Evaluating the fit of structural equation models: Tests of significance and descriptive goodness-of-fit measures. Methods of psychological research online, 8 (2), 23-74.

Schmidt, G. W., \& Stein, G. L. (1991). Sport commitment: A model integrating enjoyment, dropout, and burnout. Journal of sport and exercise psychology, 13 (3), 254-265. doi: 10.1123/jsep.13.3.254

Scotto di Luzio, S., Martinent, G., Guillet-Descas, E., \& Daigle, M. P. (2020). Exploring the role of sport sense of community in perceived athlete burnout, sport motivation, and engagement. Journal of applied sport psychology, 32 (5), 513-528. doi:10.1080/10413200.2019.1575298

Tabachnick, B., \& Fidell, L. (2007). Multivariate analysis of variance and covariance. In: Hartman S, (Ed.). Using multivariate statistics. Boston: Allyn \& Bacon; pp. 243-310.

Wheaton, B., Muthen, B., Alwin, D. F., \& Summers, G. F. (1977). Assessing reliability and stability in panel models. Sociological methodology, 8, 84-136. doi:10.2307/270754

WOS (2021, March 16). Development and preliminary validation of an athlete burnout measure. http://apps.webofknowledge.com 